\title{
Poisonings Caused by Wild Mushroom Containing Amanitin Toxins - Shaoxing City, Zhejiang Province, China, 2019
}

\author{
Xiaomin $\mathrm{Xu}^{1}$; Liang Sun ${ }^{1}$; Yizhe Zhang'; Jiayang Song ${ }^{2}$; Chao Xing ${ }^{3}$; Hongshun Zhang,
}

\section{Summary \\ What is already known about this topic?}

Among all food poisoning, poisonings caused by wild mushrooms containing amanitin toxins have the highest case fatality rate. Amanitin toxins can cause acute liver function damage, and symptoms of the poisoning can include vomiting and diarrhea in early stages and progressive liver damage 2-3 days later.

What is added by this report?

Before 2019, there were about 1-2 cases of wild mushroom containing amanitin toxins poisoning each year in Zhejiang Province. In 2019, 10 cases were identified through disease investigation and toxin detection and biological identification in Shaoxing City, Zhejiang Province. All patients had a history of wild mushroom consumption.

What are the implications for public health practice?

In the summer, some people collect the wild mushrooms for consumption. In China, about 20 species of mushrooms can cause death, and most people lack the ability to identify which mushrooms are edible. To combat this, effective science popularization and prevention and control work will be able to reduce the occurrence of related poisoning events.

\section{BACKGROUND}

From June 28 to July 15, 2019, 3 suspected poisoning events continuously occurred in Shaoxing City, Zhejiang Province, China. A total of 10 patients with different degrees of liver damage were found, and 1 patient died so the case fatality rate was $10 \%$. The agencies for disease control and prevention formed a team to investigate this incident. Using a combination of epidemiological investigations, laboratory toxin analysis, and biological identification results of poisonous samples, the poisoning events were determined to be caused by the ingestion of a wild mushroom (Amanita rimosa) containing amanitin toxins. Through popular science publicity and education on wild mushroom poisonings and the prohibition of wild mushroom collection/consumption, similar poisoning events were reduced until the middle of August.

\section{INVESTIGATION AND RESULTS}

The Xinchang County CDC of Shaoxing City, Zhejiang Province, received an event report from a local hospital that 6 patients in a family went to a doctor with suspected food poisoning on June 29, 2019. The local CDC in Shaoxing immediately carried out an epidemiological investigation and found that the patients had the gastrointestinal irritation symptoms including nausea, vomiting, and diarrhea in the early stages. The patients then developed different degrees of liver function damage with symptoms including abnormal increase of glutamic pyruvic transaminase and glutamic oxaloacetic transaminase between 40-72 hours following consumption. One patient was found to be in severe condition upon rescuing and died. All other patients had improved conditions after medical treatments and were discharged from the hospital one week later. On July 11, the Shaoxing City CDC received a report from that local hospital of another 2 patients with similar symptoms. The national, provincial, and local CDC organized a joint survey team to carry out an epidemiological investigation.

From June 22 to July 25, 2019 in Shaoxing City, Zhejiang Province, case searching was carried out. The criteria included patients with symptoms of gastrointestinal irritation such as nausea, vomiting, and diarrhea appearing in early stages and then progressing to acute liver function damage within $12-72$ hours with no obvious fever in the course of the disease.

The professionals of the local CDC carried out case searching in medical institutions within their jurisdiction by interviewing the patients that met the case definition, their families, and the medical staff involved in the treatment of the patients, collecting 
their medical records, and making household hygiene survey in the villages where the incidents occurred. The plasma/urine samples of the patients were collected and detected with $\alpha$-amanitin by the Zhejiang Provincial CDC. Wild mushrooms were collected and detected as poisonous by the Zhejiang Provincial CDC and was identified with molecular biology by China CDC.

Until July 25 , a total of 10 patients meeting the case definition were found including 6 patients in Xinchang County, 2 patients in Keqiao District, and 2 patients in Zhuji County.

All patients came from three families in Shaoxing City, which lived tens of kilometers apart. The members of the three families did not know each other, nor did they have any other common exposure factors. All patients became sick 10-22 hours after their family dinners. The consumption dates for three families were on June 27-28, July 10, and July 15. Family members who did not participate in the dinner did not become sick.

Field investigations revealed that the meals of the three families were relatively simple and mainly included fried vegetables, soups, and staple foods such as rice. All foods were cooked and eaten as soon as possible, and no individuals were in contact with raw or cold foods. The wild mushrooms were collected on mountains near their residence and were one of the main foods. From June 27 to 28, 7 people had dinner together in Xinchang County, 1 person ate noodles cooked with wild mushrooms, 6 persons (including the aforementioned individual) ate wild mushroom soup containing bamboo, and these 6 persons became sick; the remaining individual was a child who did not consume the wild mushroom and developed no disease. On July 10, 2 individuals in Keqiao District picked and ate a variety of cooked wild mushrooms for dinner. On the morning of July 11, both became sick. On July 15, 2 persons in Zhuji County ate wild mushroom soup collected by themselves for lunch and dinner, and both presented poisoning symptoms. Besides wild mushroom consumption, there were no other shared risk factor exposures between the patients. Therefore, wild mushroom consumption was identified as the exposure risk factor.

The morbidity timeline, place, and population distribution of poisoning patients are shown in Table 1.

Through interviewing the patients and their family members in three families, we found that all the wild mushrooms eaten by the patients were picked in the mountains near their residence and were white mushrooms with similar biological morphology. The investigation team immediately collected mushroom samples in the fields the patients identified. The mushrooms were confirmed by the patients and were sent to the laboratory for toxin detection and biological identification.

The clinical characteristics of all patients were as follows: 1) The latent period was between 10 hours and 22 hours; 2) the initial symptoms were gastrointestinal irritation including nausea, vomiting, abdominal pain, diarrhea, etc.; 3) 36-72 hours postconsumption of wild mushroom, liver function damage appeared and a death occurred as a result of acute liver failure; 4) about a week after of symptomatic support treatment, the liver function of the patients gradually recovered; and 5) there were no fever symptoms in the course of disease. The development of clinical symptom was consistent with the characteristics of acute toxic liver damage (1-3).

The clinical manifestations of poisoning patients are shown in Table 2.

The patients' plasma samples from their first day in the hospital were collected. The mushroom toxin $\alpha$ amanitin in samples were detected by liquid chromatography with tandem mass spectrometry (LCMS/MS). The toxins were found in 8 patients' plasma samples. The contents of $\alpha$-amanitin in plasma were between $0.016-1.11 \mathrm{ng} / \mathrm{mL}$. The toxins could not be

TABLE 1. The morbidity time, place, and population distribution of the poisoned patients

\begin{tabular}{ccccccccc}
\hline Meal events & $\begin{array}{c}\text { Total number } \\
\text { at meal }\end{array}$ & $\begin{array}{c}\text { Number of } \\
\text { consuming wild } \\
\text { mushrooms }\end{array}$ & $\begin{array}{c}\text { Poisoned } \\
\text { patients }\end{array}$ & $\begin{array}{c}\text { Poisoning } \\
\text { sites }\end{array}$ & $\begin{array}{c}\text { Time of } \\
\text { consumption }\end{array}$ & $\begin{array}{c}\text { Time of first } \\
\text { case }\end{array}$ & $\begin{array}{c}\text { Time of last } \\
\text { case }\end{array}$ & $\begin{array}{c}\text { Latent period } \\
\text { (hours) }\end{array}$ \\
\hline Xinchang 1 & $1^{*}$ & 1 & 1 & Home & Jun 27, 7:00 & Jun 27, 17:00 & - & 10 \\
Xinchang 2 & 7 & 6 & 6 & Home & Jun 28, 18:00 & Jun 29, 5:00 & Jun 29, 16:00 & $11-22$ \\
Keqiao 1 & 2 & 2 & 2 & Home & Jul 10, 17:00 & Jul 11, 8:00 & Jul 11, 8:00 & 15 \\
Zhuji 1 & 2 & 2 & 2 & Home & Jul 15, 12:00 & Jul 15, 22:00 & - & 10 \\
Zhuji 2 & 2 & 2 & 2 & Home & Jul 15, 18:00 & Jul 15, 22:00 & Jul 16, 4:00 & 10 \\
\hline
\end{tabular}

${ }^{*}$ This patient consumed the poisonous mushroom twice and died. 
TABLE 2. The clinical manifestations of the poisoned patients in the 3 areas.

\begin{tabular}{|c|c|c|c|c|}
\hline Clinical characteristics & Xinchang & Zhuji & Keqiao & Total \\
\hline \multicolumn{5}{|l|}{ Patients with gastrointestinal irritation } \\
\hline Nausea and vomiting & 5 & 2 & 2 & 9 \\
\hline Abdominal pain & 6 & 2 & 2 & 10 \\
\hline Diarrhea & 6 & 2 & 1 & 9 \\
\hline \multicolumn{5}{|l|}{ Patients with liver function damage } \\
\hline $\begin{array}{l}\text { Glutamic-pyruvic transaminase (GPT/ALT) and glutamic-oxaloacetic } \\
\text { transaminase (GOT/AST) }\end{array}$ & $\begin{array}{l}6 \text { (Up to } 55 \text { times } \\
\text { higher) }\end{array}$ & $\begin{array}{l}2 \text { (Up to } 110 \\
\text { times higher) }\end{array}$ & $\begin{array}{l}2 \text { (Up to } 25 \text { times } \\
\text { higher) }\end{array}$ & 10 \\
\hline
\end{tabular}

detected in 2 patients' plasma samples 30 hours and 50 hours post-consumption of the mushrooms. The toxins were found in 2 patients' urine samples 62 hours and 51 hours post-consumption and the contents were $0.069 \mathrm{ng} / \mathrm{mL}$ and $1.24 \mathrm{ng} / \mathrm{mL}$, respectively.

The wild mushroom samples were found to have $\alpha$ Amanitin and $\beta$-amanitin, and the average contents in the dried samples were $8.63 \mathrm{mg} / \mathrm{g}$ and $2.57 \mathrm{mg} / \mathrm{g}$, respectively.

Molecular identification was based on internal transcribed spacer (ITS) sequences. Based on morphological and molecular studies, the suspected mushroom was identified as Amanita rimosa (4-5) Figure 1. The contents of $\alpha$-amanitin and $\beta$ amanitin in the sampled mushroom specimens were similar to those in previously reported Amanita rimosa (G).

\section{PUBLIC HEALTH RESPONSE}

After the cause of poisoning was determined, the CDCs in Shaoxing city immediately carried out the popular science publicity and education about wild mushroom poisonings and prohibited residents from
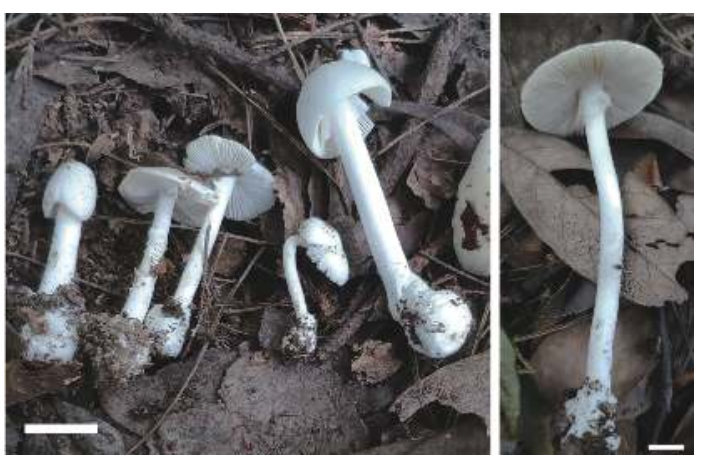

FIGURE 1. Basidioma of Amanita rimosa (white bar= $1 \mathrm{~cm}$ ). Amanita rimosa grows on the ground in broadleaved forest dominated by the Fagaceae family of trees. Basidiocarp: small; pileus: $3-5 \mathrm{~cm}$ in diameter, white to whitish, middle white to slightly darker; stipe: white to whitish; volva: white; limbate annulus: subapical, white. picking and eating wild mushrooms. No similar poisoning incidents occurred until August 15, 2019.

The local CDC also suggested regularly carrying out the popular science publicity and education of toxic mushroom poisonings before the rainy season (from the middle of June to the middle of July) in the future. They also decided to set up warning signs prohibiting the picking and eating of wild mushroom in mountain areas to prevent such incidents.

\section{DISCUSSION}

The rainy season in Zhejiang Province is from the middle of June to the middle of July every year and the average temperature is between $20{ }^{\circ} \mathrm{C}-30{ }^{\circ} \mathrm{C}$, which are suitable temperatures and humidity for the growth of wild mushrooms (7). Some local mountain residents often consume wild mushrooms, but it is difficult to distinguish edible or toxic wild mushrooms for most residents. There is the possibility of poisoning in the collection and ingestion of toxic wild mushrooms.

The case fatality rate of wild mushroom poisonings with amanitin toxin is reportedly about $20 \%$ (2). The increase in transaminase levels of poisoning patients generally occurs 48-72 hours following consumption and the optimal treatment period is before 36 hours (8). Toxin detection should occur as early as possible to determine the cause of the disease and carry out effective interventions and treatment in time.

Acknowledgement: This work was supported by Zhejiang Provincial Science Research Foundation (LGF18H260007).

doi: $10.46234 / \mathrm{ccdcw} 2020.131$

\# Corresponding author: Hongshun Zhang, zhanghs@niohp. chinacdc.cn.

\footnotetext{
${ }^{1}$ Zhejiang Provincial Center for Disease Control and Prevention, Hangzhou, Zhejiang, China; ${ }^{2}$ National Institute of Occupational Health and Poison Control, Chinese Centre for Disease Control and Prevention, Beijing, China; ${ }^{3}$ Shaoxing Center for Disease Control and Prevention, Shaoxing, Zhejiang, China.
}

Submitted: October 29, 2019; Accepted: June 18, 2020 


\section{REFERENCES}

1. Chen ZH, Zhang P, Zhang ZG. Investigation and analysis of 102 mushroom poisoning cases in Southern China from 1994 to 2012. Fungal Divers 2014;64(1):123 - 31. http://dx.doi.org/10.1007/s13225013-0260-7.

2. Garcia J, Costa VM, Carvalho A, Baptista P, de Pinho PG, de Lourdes Bastos M, et al. Amanita phalloides poisoning: mechanisms of toxicity and treatment. Food Chem Toxicol 2015;86:41 - 55. http://dx.doi.org/ 10.1016/j.fct.2015.09.008.

3. Leite M, Freitas A, Azul AM, Barbosa J, Costa S, Ramos F. Development, optimization and application of an analytical methodology by ultra performance liquid chromatography-tandem mass spectrometry for determination of amanitins in urine and liver samples. Anal Chim Acta 2013;799:77 - 87. http://dx.doi.org/10.1016/j.aca.2013.08.044.

4. Cai Q, Tulloss RE, Tang LP, Tolgor B, Zhang P, Chen ZH, et al. Multilocus phylogeny of lethal amanitas: implications for species diversity and historical biogeography. BMC Evol Biol 2014;14:143. http://dx.doi.org/ 10.1186/1471-2148-14-143.

5. Zhang P, Chen ZH, Xiao B, Tolgor B, Bao HY, Yang ZL. Lethal amanitas of East Asia characterized by morphological and molecular data. Fungal Divers 2010;42(1):119 - 33. http://dx.doi.org/10.1007/s13225010-0018-4.

6. Tang SS, Zhou Q, He ZM, Luo T, Zhang P, Cai Q, et al. Cyclopeptide toxins of lethal amanitas: compositions, distribution and phylogenetic implication. Toxicon 2016;120:78 - 88. http://dx.doi.org/10.1016/j. toxicon.2016.07.018.

7. Govorushko S, Rezaee R, Dumanov J, Tsatsakis A. Poisoning associated with the use of mushrooms: a review of the global pattern and main characteristics. Food Chem Toxicol 2019;128:267 - 79. http://dx.doi.org/ 10.1016/j.fct.2019.04.016.

8. Abuknesha RA, Maragkou A. A highly sensitive and specific enzyme immunoassay for detection of $\beta$-amanitin in biological fluids. Anal Bioanal Chem 2004;379(5):853 - 60. http://dx.doi.org/10.1007/s00 216-004-2663-5. 